\title{
Pengaruh Korean Wave dan Brand Ambassador pada Pengambilan Keputusan Konsumen
}

\author{
Amarilis Rahmadani, Yunita Anggarini ${ }^{\bowtie}$ \\ Sekolah Tinggi Ilmu Manajemen YKPN \\ e-mail: yuni74999@gmail.com
}

\begin{abstract}
This study aims to analyze the influence of the Korean wave and brand ambassadors on consumer purchasing decisions. This research is a quantitative study using a population of consumers of Nacific cosmetic products from South Korea. By using purposive sampling technique, a sample of 100 respondents was tested in this study. The analytical method used is binary logistic regression analysis. The results showed that the decision to purchase Korean cosmetic products was strongly influenced by the Korean wave, and vice versa was not influenced by the brand ambassador. This study shows that Korean culture has a fairly strong influence on Indonesian consumers' decisions to buy cosmetic products. Meanwhile, Korean influencers have no influence on purchasing decisions, which factors need to be studied. This study adds a reference to behavioral research related to the effects of cultural change in Indonesia, especially the influence of Korean culture.
\end{abstract}

Keywords: Korean wave, brand ambassador, purchasing decision

\begin{abstract}
Abstrak
Penelitian ini bertujuan untuk menganalisis pengaruh Korean wave dan brand ambassador pada keputusan pembelian konsumen. Penelitian ini merupakan penelitian kuantitatif dengan menggunakan populasi konsumen produk kosmetik Nacific dari Korea Selatan.. Dengan menggunakan teknik purposive sampling, sampel sebanyak 100 responden di uji dalam penelitian ini. Metode analisis yang digunakan adalah analisis regresi logistik biner. Hasil penelitian menunjukkan bahwa keputusan pembelian produk kosmetik korea ini, sangat dipengaruhi oleh Korean wave, dan sebaliknya tidak dipengaruhi oleh brand ambassador. Penelitian ini menunjukkan bahwa budaya Korea memiliki pengaruh yang cukup kuat pada keputusan konsumen Indonesia membeli produk kosmetik. Sedangkan influencer Korea tidak memiliki pengaruh pada keputusa pembelian, yang perlu dikaji faktor-faktor penyebabnya. Penelitian ini menambah referensi penelitian keperilakuan terkait dengan efek perubahan kultur di Indonesia, terutama pengaruh budaya korea.
\end{abstract}

Kata kunci: Korean wave, brand ambassador, keputusan pembelian 


\section{PENDAHULUAN}

Budaya merupakan salah satu faktor yang mempengaruhi keputusan pembelian (Kotler \& Armstrong, 2008). Budaya merupakan keyakinan, nilai dan kebiasaan yang dipelajari untuk mengarahkan perilaku konsumen dari anggota masyarakat tertentu (Schiffman dkk., 2012), dan terdapat budaya yang populer, banyak menarik massa dan diminati banyak orang dari berbagai negara (Sutisna, 2001). Salah satu budaya populer yang masuk ke Indonesia berasal dari Korea Selatan.

Budaya dari Korea Selatan sering disebut dengan Korean Wave atau Hallyu. Hallyu ini mengacu pada fenomena budaya populer Korea yang mulai populer pada akhir tahun 1990-an di Cina dan Asia Tenggara. Hallyu sangat populer di kalangan anak muda yang terpesona dengan musik, drama, film dan bahkan makanan Korea (Bok-rae, 2015). Dengan demikian Korean wave/hallyu adalah fenomena penyebaran budaya pop Korea Selatan secara global, yang mencakup semua bidang terkait dengan Korea seperti K-pop, K-drama, K-film, K-gaya hidup hi-tech, Kkultur, K-kuliner, K-sastra, dan K-bahasa tradisional (Nguyen, 2020).

Di Indonesia, penyebaran Korean wave/hallyu terjadi melalui drama, film, musik, makanan, kosmetik dan fashion Korea (Pramadya \& Oktaviani, 2016). Masyarakat Indonesia yang mengikuti budaya Korea Selatan memiliki kecenderungan untuk menyukai produkproduk yang digunakan oleh para selebriti Korea Selatan (Siswandi \& Djawoto, 2019). Hallyu menimbulkan minat masyarakat untuk memiliki produk tersebut dan mendorongnya untuk membuat keputusan pembelian. Hallyu telah memainkan peran penting dalam peningkatan pariwisata asing di Korea dan meningkatkan pembelian produk terkait seperti kosmetik, fashion, dan masakan Korea oleh pelanggan asing (Yu dkk. 2012). Banyak penelitian sebelumnya yang membuktikan bahwa Korean wave juga berdampak positif terhadap ekspor produk Korea dan peningkatan pembelian (Lee, 2015).

Fenomena Hallyu/Korean wave dimanfaatkan oleh beberapa perusahaan di Indonesia untuk meningkatkan penjualannya. Perusahaan-perusahaan di Indonesia yang menggunakan influencer sebagai strategi untuk meningkatkan penjualan produk adalah Mc Donald yang menggunakan artis BTS atau kosmetik Nacific yang mengangkat artis Chanyeol EXO sebagai global brand ambassador. Kedua kelompok influencer tersebut merupakan boy band dari Korea yang memiliki banyak penggemar di berbagai negara, termasuk masyarakat Indonesia.

Brand ambassador merupakan alat yang digunakan perusahaan untuk berkomunikasi dan terlibat dengan publik dengan harapan dapat meningkatkan penjualan (Lea-Greenwood, 2012). Brand ambassador merupakan wajah bagi suatu produk yang diharapkan mampu meningkatkan awareness dan minat konsumen terhadap produk tersebut, dan berdampak pada peningkatan penjualan perusahaan.

Meski pengaruh Korean wave, dan brand ambassador cukup besar pada keputusan pembelian, hasil penelitian terdahulu menunjukkan adanya inkonsistensi atau ketidaksamaan hasil antar penelitian mengenai pengaruh kedua variabel tersebut pada keputusan pembelian secara parsial. Beberapa penelitian menunjukkan bahwa variabel Korean wave berpengaruh signifikan terhadap keputusan pembelian (Sagia \& Situmorang, 2018; Siswandi \& Djawoto, 2019), dan sebaliknya penelitian yang dilakukan oleh Lestari dkk., (2019) dan Wardani \& Santosa (2020) menunjukkan bahwa Korean wave tidak memiliki pengaruh yang signifikan pada keputusan pembelian.

Demikian juga dengan hasil penelitian untuk variabel brand ambassador. Beberapa penelitian menunjukkan bahwa brand ambassador berpengaruh signifikan terhadap keputusan pembelian (Sagia \& Situmorang, 2018; 
Sriyanto \& Kuncoro, 2019), dan sebaliknya penelitian lainnya menunjukkan bahwa brand ambassador tidak memiliki pengaruh yang signiifikan pada keputusan pembelian (Lestari dkk., 2019; Wardani \& Santosa, 2020).

Berdasar hal tersebut penelitian ini bertujuan untuk menganalisis pengaruh dari Korean wave dan brand ambassador pada keputusan konsumen untuk membeli. Penelitian ini diawali dengan mengkaji literatur terkait bagaimana variabel Korean wave dan brand ambassador mempengaruhi keputusan konsumen dalam membeli produk. Kemudian menganalisis besarnya pengaruh kedua variabel tersebut pada keputusan pembelian. Dengan demikian, diharapkan hasil penelitian dapat menambah wawasan dan memberikan rekomendasi yang tepat mengenai strategi pemasaran bagi perusahaan.

Untuk melakukan analisis konten (content analysis) melalui tinjauan pustaka, bagian ini membahas teori yang mendasari penelitian antara lain (1) teori perilaku konsumen, (2) Korean wave/Hallyu, dan (3) Brand ambassador.

\section{Teori Perilaku Konsumen/Keputusan Pembelian}

Di sebagian besar istilah umum, sebuah keputusan merupakan penyeleksian yakni sebuah pilihan dari dua atau lebih pilihanpilihan alternatif. Dengan kata lain, untuk membuat keputusan, pemilihan berbagai alternatif mesti tersedia (Assael, 2004). Ketika seseorang konsumen membuat pilihan antara melakukan pembelian atau tidak melakukan pembelian, sebuah pilihan antara merek A dan merek B, atau sebuah pilihan untuk menghabiskan waktu mengerjakan $\mathrm{A}$ atau $\mathrm{B}$, maka orang ini berada pada posisi untuk membuat keputusan.

Pengambilan keputusan konsumen bukanlah proses tunggal. Keputusan untuk membeli sebuah produk mungkin membutuhkan pertimbangan dan evaluasi yang berbeda dengan produk yang lain. Proses keputusan konsumen menyajikan sebuah pedoman (road map) tentang bagaimana konsumen menemukan cara untuk mengambil keputusan pembelian. Proses ini mencakup tahap-tahap berikut: (1) Need Recognition (Pengenalan Kebutuhan), (2) Search for Information (Pencarian Informasi), (3) Evaluations of Alternatives (Evaluasi Berbagai Alternatif), (4) Purchase (Pembelian), dan (5) Postpurchase Evaluation (Evaluasi Purna Pembelian) (Assael, 2004) (lihat Gambar 1).

Keputusan pembelian adalah perilaku pembelian konsumen akhir di mana mereka membeli barang atau jasa untuk dikonsumsi (Kotler \& Armstrong, 2008). Kotler \& Keller (2016) menyatakan "consumer behavior is the study of how individuals, groups, and organizations select, buy, use, and dispose of goods, services, ideas, or experiences to satisfy their needs and wants." Keputusan pembelian tidak terlepas dari perilaku konsumen. Perilaku keputusan pembelian konsumen dipengaruhi oleh dua faktor dasar yang mempengaruhi keputusan konsumen, yaitu (1) konsumen secara individu, dan (2) faktor lingkungan (Kotler \& Keller, 2016; Assael, 2004).

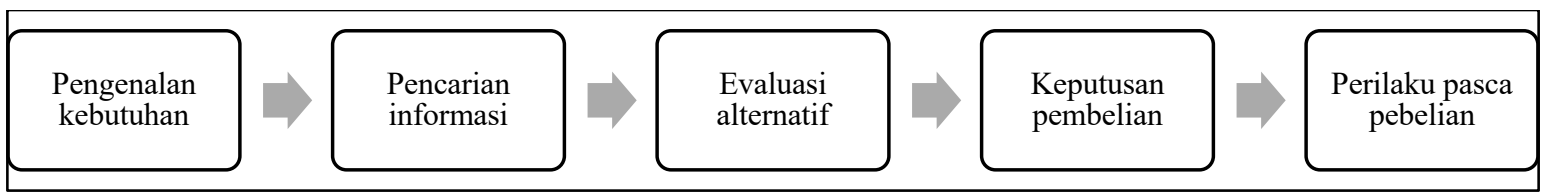

Sumber: Kotler \& Armstrong, (2018) dan Assael (2004)

Gambar 1. Proses Keputusan Pembelian

Faktor konsumen secara individu, yang ditunjukkan oleh faktor internal konsumen meliputi kebutuhan, persepsi tentang karakteristik merek, dan sikap 
konsumen terhadap berbagai alternatif merek. Selain itu, adalah faktor demografi, gaya hidup dan karakteristik kepribadian konsumen yang turut mempengaruhi pilihan merek (Assael, 2004).

Pada faktor lingkungan, lingkungan pembelian konsumen mencakup budaya (norma-norma masyarakat dan pengaruh regional/etnis subbudaya seperti Korean wave), kelas sosial (kelompok-kelompok sosioeconomic di mana konsumen berada), dan kelompok tatap muka/face to face group (teman, keluarga, dan kelompok referensi). Organisasi pemasaran juga menjadi bagian dari lingkungan konsumen, sejak organisasi ini memberikan tawaran yang dapat memuaskan kebutuhan konsumen (Assael, 2004), termasuk pemilihan influencer atau brand ambasador dan kebijakan pemasaran lainnya (LeaGreenwood, 2012; FuiYeng \& Yazdanifard, 2015).



Sumber: Assael (2004)

Gambar 2. Proses Keputusan Pembelian

\section{Korean Wave/Hallyu}

Istilah "Hallyu" atau Korean wave merupakan dua istilah yang memiliki arti yang sama dan dapat dipertukarkan (Nguyen, 2018). Pertama kali istilah tersebut muncul di Taiwan dan oleh The China Times dirujuk kepada perusahaan/produk Korea. Pada tahun 1993, Hallyu diperkenalkan melalui film Jealousy shown di Fukuoka Jepang, dan membuka era baru penaklukan Korea atas industri hiburan di Asia. Hallyu atau Korean wave adalah fenomena penyebaran budaya Korea Selatan melalui musik, film, kuliner, fashion dan bahasa (Pramadya \& Oktaviani, 2016), olahraga dan pariwisata (Nguyen, 2018).
Korean Wave atau Hallyu ini mengacu pada fenomena budaya populer Korea yang menjadi tren di China daratan dan Asia Tenggara pada akhir tahun 1990an (Bok-rae, 2015). Korean wave meningkatkan pembelian akan produkproduk terkait Korea oleh konsumen luar negeri atau pelanggan asing ( $\mathrm{Yu}$ dkk., 2012). Menurut Lee (2011), Hallyu adalah bagian terdepan dalam drama Korea dan pop Korea karena melalui dua produk budaya populer tersebut berguna untuk mempromosikan produk budaya Korea yang lain.

Korean Wave/Hallyu berevolusi mulai Hallyu 1.0 sampai 4.0, dimulai pada akhir tahun 1990-an dengan munculnya Hallyu 1.0 melalui ekspor K-drama. 
Selanjutnya muncul Hallyu 2.0 dengan Kmusic, Hallyu 3.0 dengan K-culture, dan Hallyu 4.0 dengan K-style (Nguyen, 2020).
Proyeksi perkembangan Hallyu ditunjukkan pada Tabel 1.

Tabel 1. The Past, Present and Future of Hallyu

\begin{tabular}{|c|c|c|c|}
\hline & Hallyu 1.0 & Hallyu 2.0 & Hallyu 3.0 \\
\hline Period & $1995 \sim 2005$ & 2006 to the present & Foreseeable future \\
\hline $\begin{array}{l}\text { Diffusion } \\
\text { Area }\end{array}$ & $\begin{array}{c}\text { Asia (China, Taiwan and } \\
\text { Japan) }\end{array}$ & $\begin{array}{c}\text { Asia, North America and } \\
\text { Europe }\end{array}$ & All over the world \\
\hline Target & $\begin{array}{c}\text { Media contents (K-dramas } \\
\text { and movies) } \\
\text { (Product-oriented) }\end{array}$ & $\begin{array}{c}\text { K-pop idols } \\
(\text { K-stars-oriented })\end{array}$ & $\begin{array}{l}\text { Genre-diversification } \\
\text { (Stars \& Creator } \\
\text { brandoriented) }\end{array}$ \\
\hline Cases & $\begin{array}{l}\text { "What is Love? (1992)," } \\
\text { "Winter Sonata (2002), } \\
\text { "My Sassy Girl (2001)" } \\
\text { "Jewel in the Palace (2003- } \\
\text { 2004)," } \\
\text { HOT (band), Boa (singer). }\end{array}$ & $\begin{array}{c}\text { Girls' Generation, Kara, } \\
\text { Shinee, 2PM, and Big Bang } \\
(\text { band })\end{array}$ & \\
\hline $\begin{array}{l}\text { Early } \\
\text { Distribution }\end{array}$ & Overseas Korean society & $\begin{array}{l}\text { Online circulation } \\
\quad \text { (YouTube) }\end{array}$ & SNS \\
\hline Media & $\begin{array}{l}\text { Video, CD, spot broad } \\
\text { casting }\end{array}$ & $\begin{array}{l}\text { Internet, on-site } \\
\text { performance }\end{array}$ & Cross-media \\
\hline Durability & $\begin{array}{c}\text { From several months to } \\
\text { years } \\
\text { (Winter Sonata) }\end{array}$ & $\begin{array}{l}\text { For several years } \\
\text { (Girls' Generation) }\end{array}$ & For several decades \\
\hline Directivity & $\begin{array}{l}\text { Turning the eyes of the } \\
\text { world upon Korea } \\
\text { (Tourist industry-centered) }\end{array}$ & $\begin{array}{l}\text { Overseas expansion and } \\
\text { performance }\end{array}$ & $\begin{array}{l}\text { To the world beyond } \\
\text { Korea (Regarded as } \\
\text { mainstream) }\end{array}$ \\
\hline
\end{tabular}

Sumber: Bok-rae (2015)

Fenomena penyebaran budaya Korea Selatan dapat mempengaruhi keputusan pembelian konsumen (Sagia \& Situmorang, 2018). Apabila seseorang menyukai produk-produk budaya Korea Selatan seperti drama, film maupun musik korea, maka semakin besar peluang orang tersebut membeli barang yang berkaitan dengan produk budaya Korea Selatan (Lestari dkk., 2019). Penelitian terdahulu menunjukkan bahwa Korean wave berpengaruh signifikan terhadap keputusan pembelian (Sagia \& Situmorang, 2018; Siswandi \& Djawoto, 2019). Hal ini menunjukkan ketidaksamaan dengan penelitian yang dilakukan oleh Lestari dkk., (2019) dan Wardani \& Santosa (2020) yang menunjukkan bahwa tidak ada pengaruh signifikan dari Korean wave terhadap keputusan pembelian. Berdasarkan uraian tersebut, dirumuskan hipotesis bahwa:

$\mathrm{H}_{1}$ : Korean Wave berpengaruh positif dan signifikan terhadap keputusan pembelian produk kosmetik Nacific

\section{Brand Ambassador}

Brand ambassador adalah alat yang digunakan perusahaan untuk berkomunikasi dan terlibat dengan publik dengan harapan dapat meningkatkan penjualan (Lea-Greenwood, 2012). Menurut Doucett (2008) "A brand ambassador is anyone who is passionate with the brand, willing to talk about the brand, loves the brand, and spreads the 
word about the brand." Brand ambassador adalah instrumen yang digunakan oleh perusahaan untuk berkomunikasi dan terhubung dengan komunitas, tentang bagaimana mereka dapat meningkatkan penjualan. Brand ambassador dapat dijadikan acuan penilaian dan persepsi konsumen terhadap suatu merek atau brand secara keseluruhan (Mudzakir, 2018).

Brand ambassador dapat memberikan pengaruh terhadap keputusan pembelian seseorang. Brand ambassador merupakan identitas dari suatu produk, semakin baik citra seorang brand ambassador maka akan semakin tinggi minat konsumen untuk membeli produk tersebut (Sagia \& Situmorang, 2018). Dalam penelitian terdahulu ditemukan hasil bahwa brand ambassador berpengaruh signifikan terhadap keputusan pembelian (Sagia \& Situmorang, 2018; Sriyanto \& Kuncoro, 2019b) sedangkan penelitian lain ditemukan hasil bahwa brand ambassador tidak berpengaruh signifikan terhadap keputusan pembelian (Lestari dkk., 2019; Wardani \& Santosa, 2020). Dengan demikian dapat diajukan hipotesis bahwa:

$\mathrm{H}_{2}$ : Brand Ambassador berpengaruh positif dan signifikan terhadap keputusan pembelian produk kosmetik Nacific

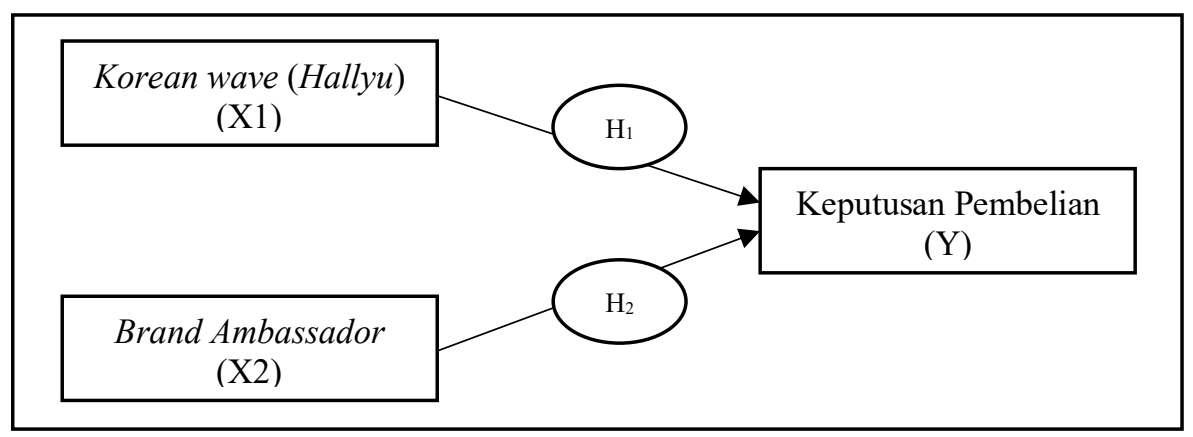

Gambar 3. Kerangka Penelitian

\section{METODE PENELITIAN}

Penelitian ini merupakan penelitian kuantitatif dengan menggunakan kuesioner sebagai metode dalam pengumpulan data. Metode survei merupakan metode penelitian kuantitatif untuk memperoleh data melalui kuesioner, wawancara dan sebagainya (Sugiyono, 2019). Dasar pertimbangan penggunaan metode survei adalah karena survei merupakan metode yang tepat untuk mendapatkan data mengenai sikap, motivasi, dan preferensi konsumen dalam suatu penelitian deskriptif (Aaker dkk., 2004; Maholtra, 2004).

Variabel penelitian meliputi variabel independen yang terdiri dari Korean wave (Hallyu), Brand ambassador dan variabel dependen yakni keputusan pembelian. Berikut ditunjukkan definisi operasional setiap variabel disertai indikatorindikatornya (lihat Tabel 2)
Objek dalam penelitian ini adalah keputusan pembelian, Korean wave, dan brand ambassador. Subjek dalam penelitian ini adalah masyarakat di Yogyakarta yang berusia minimal 17 tahun.

Populasi dalam penelitian ini adalah seluruh konsumen yang pernah menggunakan atau membeli produk kosmetik Korea Selatan yakni merek Nacific yang berdomisili di Yogyakarta. Metode pengambilan sampel dalam penelitian ini menggunakan non probability sampling- purposive sampling. Purposive Sampling yaitu teknik pengambilan sampel dengan kriteria atau pertimbangan tertentu (Sugiyono, 2019). Sampel yang dipilih memenuhi kriteria: (1) Responden berusia minimal 17 tahun (2) Responden berdomisili di Yogyakarta, dan (3) Responden pernah membeli/ menggunakan merek Nacific. Untuk menentukan ukuran sampel, agar diperoleh kecukupan sampel 
maka peneliti perlu memperhatikan jumlah variabel yang diteliti dan kesesuaian dengan model analisis yang digunakan, dengan ketentuan jumlah sampel minimal yang diambil memakai ketentuan sebagai berikut yakni 5 kali item pernyataan/pertanyaan. Oleh karena itu besar sampel yang digunakan dalam penelitian ini sebanyak 65 responden (pembulatan 100 reponden).

Tabel 2. Definisi Operasional

\begin{tabular}{|c|c|c|}
\hline Definisi Operasional Varibel & Dimensi & Skala Pengukuran \\
\hline $\begin{array}{l}\text { Korean Wave adalah sejauh } \\
\text { mana penyebaran produk budaya } \\
\text { Korea Selatan dalam bentuk } \\
\text { seperti musik, film, makanan } \\
\text { fashion dan bahasa dapat } \\
\text { diterima oleh konsumen } \\
\text { (Pramadya \& Oktaviani, 2016). }\end{array}$ & $\begin{array}{l}\text { Korean Wave dapat diukur dengan } \\
3 \text { indikator, yaitu: (Febriana dkk., } \\
2017 \text { ) } \\
\text { (1) Bahasa Korea; } \\
\text { (2) Drama Korea; dan } \\
\text { (3) Musik Korea (K-pop). }\end{array}$ & $\begin{array}{ll}\text { Skala Likert }(1-5) \text { : } \\
\text { 1. } & \text { Sangat tidak setuju } \\
\text { 2. } & \text { Tidak setuju } \\
\text { 3. } & \text { Netral } \\
\text { 4. } & \text { Setuju } \\
\text { 5. } & \text { Sangat setuju }\end{array}$ \\
\hline $\begin{array}{l}\text { Brand ambassador merupakan } \\
\text { ikon budaya atau identitas suatu } \\
\text { produk dan bertindak sebagai } \\
\text { alat pemasaran yang mewakili } \\
\text { suatu produk (Sagia \& } \\
\text { Situmorang, 2018). }\end{array}$ & $\begin{array}{l}\text { Brand Ambassador dapat diukur } \\
\text { dengan } 4 \text { indikator, yaitu: Sagia \& } \\
\text { Situmorang (2018) } \\
\text { (1) Visibility (kepopuleran) } \\
\text { (2) Credibility (kredibilitas) } \\
\text { (3) Attraction (daya tarik) } \\
\text { (4) Power (kekuatan) }\end{array}$ & $\begin{array}{ll}\text { Skala Likert (1-5): } \\
\text { 1. } & \text { Sangat tidak setuju } \\
\text { 2. } & \text { Tidak setuju } \\
\text { 3. } & \text { Netral } \\
\text { 4. } & \text { Setuju } \\
\text { 5. } & \text { Sangat setuju }\end{array}$ \\
\hline $\begin{array}{l}\text { Keputusan pembelian adalah } \\
\text { kegiatan dimana seorang } \\
\text { konsumen membeli suatu produk } \\
\text { (Sagia \& Situmorang, 2018; } \\
\text { Assael, 2004). }\end{array}$ & $\begin{array}{l}\text { Indikator dari keputusan pembelian } \\
\text { ada } 2 \text {, yaitu: } \\
\text { (1) Melakukan pembelian } \\
\text { (2) Tidak melakukan pembelian }\end{array}$ & $\begin{array}{ll}\text { Skala Likert }(1-5) \text { : } \\
\text { 1. } & \text { Sangat tidak setuju } \\
\text { 2. } & \text { Tidak setuju } \\
\text { 3. } & \text { Netral } \\
\text { 4. } & \text { Setuju } \\
\text { 5. } & \text { Sangat setuju }\end{array}$ \\
\hline
\end{tabular}

Sumber: Sagia \& Situmorang (2018), Febriana dkk. (2017), Pramadya \& Oktaviani (2016), Aldoko \& Yuliyanto (2016), dan Assael (2004)

\section{Alat Analisis}

Penelitian ini menggunakan model regresi logistik biner karena variabel dependennya merupakan variabel yang sifatnya dikotomi dengan 2 kategori. Variabel dependen yang digunakan dalam penelitian ini adalah skala nominal di mana responden yang melakukan pembelian termasuk kategori 1 dan responden yang tidak melakukan pembelian termasuk kategori 0 . Regresi logistik tidak memerlukan asumsi normalitas data pada variabel independennya (Ghozali, 2018). Regresi logistik digunakan untuk menguji pengaruh Korean wave, dan brand ambassador terhadap keputusan pembelian.

Untuk melakukan uji hipotesis, penulis menggunakan serangkaian uji. (1) Uji Overall Model Fit (Menilai Model Fit), (2) Uji kelayakan model regresi logistik, (3) Uji Koefisien Determinasi Nagelkerke $R$ Square, dan (4) Uji Wald Test. Uji Overall Model Fit adalah uji yang dilakukan untuk mengetahui apakah variabel bebas (independen) dalam regresi logistik secara simultan berpengaruh terhadap variabel terikat (dependen) (Widarjono, 2015). Untuk Uji kelayakan model regresi logistik, penelitian ini menggunakan Hosmer and Lemeshow's Goodness of Fit Test (Ghozali, 2018). Sedangkan uji Koefisien Determinasi menggunakan teknik Nagelkerke R Square. Nagelkerke R Square merupakan ukuran yang dilakukan untuk mengetahui seberapa besar variabel independen mampu menjelaskan dan mempengaruhi variabel dependen. Pada akhirnya dilakukan Uji Wald. Uji Wald merupakan uji signifikansi variabel independen pada analisis regresi logistik. Uji Wald dalam regresi logistik digunakan untuk mengetahui ada tidaknya pengaruh dari variabel independen terhadap variabel dependen secara parsial (Widarjono, 2018). 


\section{HASIL DAN PEMBAHASAN Karakteristik Responden}

Karakteristik responden yang diamati dalam penelitian ini meliputi faktor jenis kelamin, usia, pekerjaan, pendapatan/penghasilan, dan pengetahuan tentang produk kosmetik Nacific. Berdasarkan jenis kelamin menunjukkan bahwa responden dengan jenis kelamin laki-laki sebanyak 22 responden atau 22,4\% dan perempuan sebanyak 78 responden atau $77,6 \%$. Berdasarkan usia bahwa jumlah responden terbanyak adalah dengan usia 17-21 tahun sebesar 59,2\%, usia 22-26 tahun sebesar $35,7 \%$, dan responden dengan usia $>26$ tahun sebesar 5,1\%.

Berdasarkan pekerjaan, karakteristik responden terbanyak adalah responden yang bekerja sebagai pelajar/mahasiswa sebesar $82,7 \%$, wiraswasta sebesar 10,2\%, dan karyawan sebesar 7,1\%. Berdasarkan penghasilan, responden terbanyak adalah reponden dengan penghasilan $<\mathrm{Rp}$ 1.000 .000 sebanyak $59,2 \%$, dan paling sedikit adalah responden dengan berpenghasilan $>$ Rp 5.000.000 sebanyak $6,1 \%$. Berdasar pengetahuan tentang produk, responden yang mengetahui produk skincare Korea sebanyak 90,8\% sedangkan responden yang tidak mengetahui produk skincare Korea sebanyak 9,2\%.

\section{Uji Validitas}

Uji Validitas adalah menguji seberapa baik pengukuran mewakili yang seharusnya diukur. Pada penelitian ini uji Validitas dilakukan dengan menggunakan Bivariate Correlations Pearson, dengan tingkat signifikansi $5 \%$, jumlah data $98, \mathrm{df}=98-2=$ 96, dan $\mathrm{r}$ tabel sebesar 0,1986. Kriteria pengambilan keputusan yang digunakan adalah (1) apabila nilai $r$ hitung $>\mathrm{r}$ tabel maka instrumen kuesioner dinyatakan valid, dan (2) apabila $r$ hitung $<$ r tabel maka instrumen dinyatakan tidak valid. Hasil perhitungan uji validitas menunjukkan bahwa hasil uji validitas yang dilakukan pada setiap pernyataan dari variabel Korean wave, dan brand ambassador menunjukkan nilai $\mathrm{r}$ hitung lebih besar daripada nilai $\mathrm{r}$ tabel. Dengan demikian dapat disimpulkan bahwa semua item pernyataan pada variabel Korean wave, dan brand ambassador adalah valid, sehingga layak untuk dijadikan instrumen penelitian.

\section{Uji Reliabilitas}

Uji reliabilitas pada penelitian ini dilakukan dengan mengukur item total korelasi dan Cronbach's Alpha. Dengan menggunakan signifikansi $5 \%$ dan variabel dikatakan reliable apabila nilai Cronbach's Alpha $(\alpha)$ $>0,70$. Hasil menunjukkan bahwa seluruh item memiliki nilai Cronbach's Alpha diatas 0,7. Dengan demikian dapat disimpulkan semua item pernyataan pada variabel Korean wave, dan brand ambassador adalah andal untuk dijadikan instrumen penelitian.

\section{Uji Keseluruhan Model (Overall Model}

\section{Fit)}

Overall Model Fit adalah uji yang dilakukan untuk mengetahui apakah variabel bebas (independen) dalam regresi logistik secara simultan berpengaruh terhadap variabel terikat (dependen). Pada penelitian ini dilakukan dengan uji Omnibus Test.

Hasil penelitian menunjukkan bahwa nilai Chi Square hitung sebesar 100,351 dengan $d f$ 3. Oleh karena nilai Chi Square hitung $(100,351)>$ nilai Chi Square tabel $(7,8147)$ atau dengan signifikansi sebesar $0,000<0,05$, maka $\mathrm{H}_{0}$ ditolak. Hal ini menunjukkan bahwa Korean wave, dan brand ambassador secara simultan berpengaruh terhadap keputusan pembelian.

\section{Uji Kelayakan Model}

Uji kelayakan model pada regresi logistik dilakukan dengan Hosmer and Lemeshow Test. Uji ini dilakukan untuk menguji hipotesis nol bahwa data empiris cocok atau sesuai dengan model. Hasil penelitian menunjukkan bahwa nilai signifikansi $(0,998)>0,05$ maka H0 diterima. Dengan demikian model yang digunakan sudah 
Pengaruh Korean Wave dan Brand Ambassador ... Keputusan Konsumen (Rahmadani, Anggarini)

cocok dengan data sehingga model regresi logistik layak untuk digunakan.

\section{Uji Koefisien Determinasi (Nagelkerke $R$ Square)}

Penelitian ini menguji koefisien determinasi dengan menggunakan teknik Nagelkerke $R$ Square. Nagelkerke $R$ Square merupakan uji yang dilakukan untuk mengetahui seberapa besar variabel independen mampu menjelaskan dan mempengaruhi variabel dependen. Nilai Nagelkerke $R$ Square merupakan nilai koefisien determinasi pada model regresi logistik. Hasil penelitian menunjukkan bahwa nilai Nagelkerke $R$
Square sebesar 0,873 yang artinya kemampuan variabel bebas (independen) dalam menjelaskan variabel terikat (dependen) adalah sebesar 0,873 atau $87,3 \%$ sedangkan sisanya $12,7 \%$ dijelaskan oleh faktor lain di luar variabel penelitian.

\section{Uji Wald dan Odds Ratio}

Uji Wald merupakan uji hipotesis yang dilakukan secara parsial. Uji wald dilakukan untuk mengetahui pengaruh variabel independen (bebas) secara parsial terhadap variabel dependen. Hasil uji wald dapat dilihat pada Tabel 3.

Tabel 3. Hasil Uji Wald

\begin{tabular}{lrrrccccc}
\hline & \multirow{2}{*}{ B } & S.E. & \multirow{2}{*}{ Wald } & df & \multirow{2}{*}{ Sig. } & \multirow{2}{*}{$\operatorname{Exp}(\mathbf{B})$} & \multicolumn{2}{c}{$\mathbf{9 5 \%}$ C.I. for } \\
\hline X1_Korean_wave & 2,299 & 1,093 & 4,421 & 1 & 0,035 & 9,962 & 1,169 & 84,913 \\
X2_Brand_ambassador & 1,653 & 1,069 & 2,389 & 1 & 0,122 & 5,222 & 0,642 & 42,480 \\
Constant & $-36,112$ & 9,785 & 13,620 & 1 & 0,000 & 0,000 & & \\
\hline
\end{tabular}

Sumber: Data primer diolah, 2021

Berdasarkan hasil uji Wald pada Tabel 3 maka diperoleh hasil sebagai berikut, variabel Korean wave memperoleh nilai Wald sebesar 4,421 dengan nilai signifikansi 0,035 . Nilai uji wald $(4,421)>$ chi square tabel $(3,8415)$ dan nilai signifikansi $0,035<0,05$ maka dapat disimpulkan bahwa hipotesis diterima. Dengan demikian variabel Korean wave secara parsial berpengaruh positif dan signifikan terhadap keputusan pembelian.

Koefisien B pada variabel Korean wave bertanda positif $(+)$ menunjukkan bahwa seseorang yang terkena dampak Korean wave memiliki kecenderungan untuk melakukan pembelian produk Nacific. Variabel Korean wave memiliki nilai odds ratio sebesar 9,962 yang artinya semakin seseorang terdampak Korean wave maka akan meningkat kecenderungan seseorang melakukan pembelian sebanyak 9,962 kali lebih tinggi dibandingkan dengan orang yang tidak terkena dampak Korean wave.

Tabel 3 juga menunjukkan nilai Wald pada variabel Brand ambassador sebesar 2,389 dengan nilai signifikansi 0,122. Nilai uji Wald $(2,389)<$ chi square tabel $(3,8415)$ dan nilai signifikansi $0,122>0,05$ maka dapat disimpulkan bahwa hipotesis ditolak. Artinya variabel brand ambassador secara parsial berpengaruh secara positif dan tidak signifikan terhadap keputusan pembelian produk Nacific.

Penggunaan brand ambassador tidak berpengaruh pada keputusan pembelian seorang konsumen. Variabel brand ambassador memiliki nilai odds ratio sebesar 5,222 yang artinya penggunaan brand ambassador akan meningkatkan kecenderungan seseorang melakukan pembelian sebanyak 5,222 kali lebih tinggi dibandingkan dengan tidak menggunakan brand ambassador.

\section{Persamaan Regresi Logistik}

Persamaan regresi logistik dengan menggunakan dua variabel independen adalah sebagai berikut.

$K P=-36,112+2,299 K W+1,653 B A . .(1)$

Keterangan:

$\mathrm{KP}=$ Keputusan Pembelian 
$\mathrm{KW}=$ Korean wave

BA = Brand ambassador

Berdasar persamaan di atas dapat dijelaskan bahwa nilai konstanta ( $\boldsymbol{\alpha})$ sebesar -36,112. Artinya jika Korean wave, dan brand ambassador memiliki nilai 0 maka keputusan pembelian konsumen adalah negatif yakni sebesar -36,112.

Nilai koefisien regresi variabel Korean wave $\left(\boldsymbol{\beta}_{1}\right)$ bernilai positif sebesar 2,299 . Artinya jika nilai Korean wave naik sebesar 1 maka perilaku keputusan pembelian konsumen akan mengalami peningkatan sebesar 2,299.

Nilai koefisien regresi variabel brand ambassador $\left(\boldsymbol{\beta}_{2}\right)$ bernilai positif yakni sebesar 1,653. Artinya jika nilai brand ambassador naik sebesar 1 maka perilaku keputusan pembelian konsumen akan mengalami peningkatan sebesar 1,653 .

\section{Pengaruh Korean Wave terhadap Keputusan Pembelian}

Berdasarkan hasil pengujian hipotesis secara parsial, Korean wave berpengaruh positif dan signifikan terhadap keputusan pembelian. Salah satu faktor yang mempengaruhi keputusan pembelian adalah budaya. Budaya adalah seperangkat nilainilai dasar, persepsi, keinginan, dan perilaku yang pelajari oleh masyarakat (Kotler \& Armstrong, 2018). Dalam penelitian ini, budaya yang dimaksud adalah Korean wave. Produk Korean wave seperti kpop dan kdrama sangat digemari masyarakat terutama anak muda. Seiring diterimanya kpop dan kdrama dalam masyarakat, produk-produk Korean wave lain juga diterima seperti fashion, kuliner, dan kosmetik. Semakin seseorang terdampak Korean wave maka besar kemungkinan seseorang melakukan keputusan pembelian berdasarkan minatnya terhadap budaya Korea. Seseorang yang menyukai film, drama korea, atau musik korea, maka orang tersebut memiliki kecenderungan untuk beli produk-produk yang berkaitan dengan produk musik, drama atau film Korea seperti CD/DVD album dari musisi Korea dan produk lain yang ditampilkan dalam drama atau film Korea (Lestari dkk., 2019).

Hasil penelitian ini mendukung penelitian yang dilakukan oleh Sagia \& Situmorang (2018) dan Siswandi \& Djawoto (2019) yang menyatakan bahwa Korean wave berpengaruh secara positif dan signifikan. Di sisi lain, hasil penelitian ini tidak sejalan dengan penelitian yang dilakukan oleh Lestari dkk., (2019) dan Wardani \& Santosa (2020) yang menyatakan bahwa Korean wave tidak berpengaruh secara signifikan terhadap keputusan pembelian. Budaya Korea mempunyai daya tarik tersendiri bagi penikmatnya. Saat seseorang menyukai produk Korean wave besar kemungkinan orang tersebut akan membeli produk yang berkaitan dengan Korean wave itu sendiri. Penyebaran Korean wave dimanfaatkan oleh brand Nacific untuk memasuki pasar luar negeri termasuk Indonesia. Nacific melihat peluang bahwa produk Korean wave terutama musik kpop dan kdrama sangat diminati oleh masyarakat sehingga Nacific memanfaatkan fenomena Korean wave sebagai strategi dalam memasarkan produknya di luar negeri.

Penelitian ini mendukung penyataan bahwa Korean wave meningkatkan pembelian akan produk-produk terkait Korea oleh konsumen luar negeri atau pelanggan asing (Yu dkk., 2012). Hal ini karena fenomena Korean wave merupakan penyebaran dari produk-produk Korea itu sendiri seperti kpop, kdrama, film, fashion, dan kuliner.

\section{Pengaruh Brand Ambassador terhadap Keputusan Pembelian}

Berdasarkan hasil pengujian hipotesis secara parsial, brand ambassador berpengaruh positif dan tidak signifikan terhadap keputusan pembelian. Arah postitif ini berarti semakin baik brand ambassador maka keputusan pembelian juga akan meningkat. Menurut Doucett (2008) brand ambassador adalah siapapun yang bersemangat dengan merek, mau 
berbicara tentang merek, menyukai merek, dan menyebarkan berita tentang merek. Chanyeol EXO memiliki image bersih dan ceria sehingga dipilih sebagai brand ambassador Nacific dan diharapkan dapat meningkatkan penjualan produk Nacific dengan image yang dimilikinya. Namun, dalam penelitian ini Chanyeol EXO sebagai brand ambassador memiliki pengaruh yang lemah terhadap keputusan pembelian. Hal ini dapat disebabkan karena dalam praktiknya, Chanyeol EXO lebih bertindak sebagai bintang iklan saja, bukan bertindak sebagai brand ambassador. Dalam hal kredibilitas, Chanyeol EXO kurang mampu memberikan informasi kepada konsumen mengenai brand Nacific. Hal ini dapat disebabkan karena profesi Chanyeol EXO sebagai musisi bukan ahli dalam hal kosmetik atau perawatan kulit. Chanyeol EXO kurang berperan dalam menyebarkan berita tentang merek seperti mempromosikan atau melakukan endorsement melalui sosial media pribadinya.

Hasil penelitian ini mendukung penelitian yang dilakukan oleh Lestari dkk., (2019) dan Wardani \& Santosa (2020) yang menyatakan bahwa brand ambassador tidak berpengaruh secara signifikan terhadap keputusan pembelian. Namun, hasil penelitian ini kontradiktif dengan penelitian yang dilakukan oleh Sagia \& Situmorang (2018) dan Sriyanto \& Kuncoro (2019) yang menyatakan bahwa brand ambassador berpengaruh positif dan signifikan terhadap keputusan pembelian.

Dalam penelitian ini brand ambassador bukan merupakan alasan utama seorang konsumen membeli produk. Menurut Simpson (2019) di website calamitycool.com, terdapat 5 (lima) faktor yang dipertimbangkan konsumen sebelum membeli produk kosmetik, yaitu brand. harga, ingredients atau bahan-bahan yang digunakan, skin type atau jenis kulit, dan use atau penggunaan. Use atau penggunaan yang dimaksudkan adalah kebutuhan pada setiap kulit berbeda-beda. Beda kebutuhan kulit, maka akan berbeda pula produk yang digunakan.

\section{SIMPULAN}

Korean wave berpengaruh secara positif dan signifikan terhadap keputusan pembelian. Penelitian ini menunjukkan bahwa fenomena Korean wave berdampak pada perilaku pembelian konsumen. Penyebaran budaya Korea melalui fenomena Korean wave memberikan pengaruh pada minat konsumen untuk membeli produk yang berasal dari Korea Selatan. Semakin seseorang menyukai produk Korean wave maka besar kemungkinan untuk membeli produk yang berkaitan dengan Korean wave itu sendiri.

Brand ambassador berpengaruh positif, namun tidak signifikan terhadap keputusan pembelian. Semakin baik brand ambassador maka keputusan pembelian seorang konsumen juga akan meningkat. Namun, dalam penelitian ini brand ambassador bukanlah faktor utama yang menentukan keputusan pembelian seorang konsumen. Selain brand ambassador, konsumen memiliki pertimbangan lain sebelum melakukan pembelian produk.

Pemanfaatan fenomena Korean wave dengan baik dapat mempengaruhi keputusan pembelian konsumen. Hasil penelitian ini dapat dijadikan sebagai referensi baik untuk brand Nacific maupun perusahaan kosmetik lain dalam strategi meningkatkan penjualan. Masuknya fenomena Korean wave ke Indonesia dapat dijadikan peluang untuk menciptakan produk baru.

Hasil penelitian menunjukkan bahwa tidak ada pengaruh antara brand ambassador dengan keputusan pembelian, dan bertolak belakang dengan teori dan hasil penelitian sebelumnya. Oleh karena itu perlu dikaji lebih lanjut faktor yang menyebabkan brand ambassador tersebut kurang memberi pengaruh. Sangat mungkin bahwa pilihan brand ambassadornya kurang tepat untuk produk kosmetik, karena brand ambassador yang dipilih adalah kelompok boy band EXO yang identik 
dengan sekumpulan pria dalam sebuah band musik.

\section{REFERENSI}

Aaker, D. A., Kumar, V., \& Day, G.S. (2004). Marketing Research. Eight Edition. Jakarta: Gramedia Pustaka.

Aldoko, D., \& Yuliyanto, E. (2016). Pengaruh Green Marketing Terhadap Citra Merek dan Dampaknya pada Keputusan Pembelian (Survei pada Mahasiswa Fakultas Ilmu Administrasi 2012/2013 Universitas Brawijaya yang Melakukan Pembelian Produk Tupperware). Jurnal Administrasi Bisnis, 40(2), 17-23.

Assael, H. (2004), Consumer Behavior \& Marketing Action (6th ed.), Cincinnati, Ohio: South-Westerrn College Publishing.

Bok-rae, K. (2015). Past, Present and Future of Hallyu (Korean Wave). American International Journal of Contemporary Research, 5(5), 154-160.

Doucett, E. (2008). Creating Your Library Brand: Communicating Your Relevance and Value to Your Patrons. American Library Association.

Febriana, R. M., Sampurno, \& Djohasjah. (2017). Pengaruh Brand Ambassador dan Hallyu terhadap Keputusan Konsumen Melakukan Brand Switching dan Implikasinya terhadap Kepuasan Konsumen Kosmetik di Jakarta. Jurnal Ekonomi, 19(3), 299-313.

FuiYeng, W., \& Yazdanifard, R. (2015). Green Marketing: A Study of Consumers' Buying Behavior in Relation to Green Products. Global Journal of Management and Business Research: E Marketing, 15(5), 16-23.

Ghozali, I. (2018). Aplikasi Analisis Multivariate Dengan Program
IBM SPSS 25 (9th ed.). Badan Penerbit Universitas Diponegoro.

Kotler, P., \& Armstrong, G. (2008). Prinsip-prinsip Pemasaran Jilid 1 (12th ed.). Penerbit Erlangga.

Kotler, P., \& Armstrong, G. (2018). Principles of Marketing (17th ed.). Pearson Education Inc.

Kotler, P., \& Keller, K. L. (2016). Maarketing Management (15th ed.). Pearson Education Inc.

Lea-Greenwood, G. (2012). Fashion Marketing Communications. John Wiley \& Sons, Ltd.

Lee, S. J. (2011). The Korean Wave: The Seoul of Asia. The Elon Journal of Undergraduate Research in Communications, 2(1), 5-93.

Lee, W. J. (2015). Korean Stars on the TV Drama and Their Influence to Foreign Fan's Behavior, Advanced Science and Technology Letters, 102, 79-82.

Lestari, H., Sunarti, \& Bafadhal, A. S. (2019). Pengaruh brand ambassador dan Korean wave terhadap citra merek serta dampaknya pada keputusan pembelian (Survei online pada konsumen Innisfree di Indonesia dan China). Jurnal Administrasi Bisnis, 66(1), 67-78.

Malhotra, N. K. (2004). Riset Pemasaran, Pendekatan Terapan. Edisi Bahasa Indonesia. Jakarta: PT Indeks Kelompok Gramedia.

Mudzakir, F. (2018). The Influence of Brand Ambassador Usage Toward Brand Image of Oppo. Industrial Research Workshop and National Seminar, 648-655.

Nguyen, X. T. (2018). The Impact of Hallyu 4. 0 and Social Media on Korean Products Purchase Decision of Generation C in Vietnam. Journal of Asian Finance, Economics, and Business, 5(3), 81-93.

Nguyen, X. T. (2020). Factors that influence the intentions to revisit Korea of Vietnamese tourists. The 
Journal of Asian Finance, Economics, and Business, 7(4), 247-258.

Pramadya, T. P., \& Oktaviani, J. (2016). Hallyu (Korean Wave) as Part of South Korea's Cultural Diplomacy and Its Impact on Cultural Hybridity in Indonesia. Jurnal Dinamika Global, 1(01), 87-116.

Sagia, A., \& Situmorang, S. H. (2018). Pengaruh Brand Ambassador, Brand Personality dan Korean Wave terhadap Keputusan Pembelian Produk Nature Republic Aloe Vera. Jurnal Manajemen Dan Bisnis Indonesia, 5(2), 286-298.

Schiffman, L. G., Kanuk, L. L., \& Hansen, H. (2012). Consumer Behaviour: A European Outlook (2nd ed.). Pearson Education Inc.

Simpson, C. (2019, June 17). Top Factors to Consider When Buying Skin Care Products. The Calamity Cool. https://www.calamitycool.com/20 19/06/top-factors-to-considerwhen-buying-skin-care-products/

Siswandi, R. A., \& Djawoto. (2019). Pengaruh Celebrity Endorser, Korean Wave, Brand Image, Word of Mouth terhadap Keputusan
Pembelian. Jurnal Ilmu Dan Riset Manajemen, 8(9), 1-18.

Sriyanto, A., \& Kuncoro, A. W. (2019). Pengaruh Brand Ambassador, Minat Beli, dan Testimoni terhadap Keputusan Pembelian. Jurnal Ekonomika Dan Manajemen, 8(1), 21-34.

Sugiyono. (2019). Metode Penelitian Kuantitatif, Kualitatif dan $R \& D$. Alfabeta.

Sutisna. (2001). Perilaku Konsumen \& Komunikasi Pemasaran. PT Remaja Rosdakarya.

Wardani, E. S., \& Santosa, A. (2020). Pengaruh Hallyu, Ambassador Merek dan Citra Merek terhadap Keputusan Pembelian atas Produk Republik Natur di Yogyakarta. Jurnal Apresiasi Ekonomi, 8(2), 203-211.

Widarjono, A. (2015). Analisis Multivariat Terapan. UPP STIM YKPN.

Widarjono, A. (2018). Analisis Regresi Dengan SPSS (1st ed.). UPP STIM YKPN.

$\mathrm{Yu}$, H., Kim, C., \& Kim, H. (2012). Investigating Cosmetic Purchase of International Tourists in South Korea. International Journal of Management Cases, 14(1), 398410. 
